Bull. Chem. Soc. Ethiop. 2020, 34(1), 175-191.

ISSN 1011-3924

(C) 2020 Chemical Society of Ethiopia and The Authors

Printed in Ethiopia

DOI: https://dx.doi.org/10.4314/bcse.v34i1.17

\title{
OPTIMUM PREDICTION FOR INHIBITION EFFICIENCY OF SAPIUM ELLIPTICUM LEAF EXTRACT AS CORROSION INHIBITOR OF ALUMINUM ALLOY (AA3003) IN HYDROCHLORIC ACID SOLUTION USING ELECTROCHEMICAL IMPEDANCE SPECTROSCOPY AND RESPONSE SURFACE METHODOLOGY
}

\author{
Onukwuli Okechukwu Dominic ${ }^{1}$, Anadebe Valentine Chikaodili ${ }^{2 *}$ and Okafor Chizoba Sandra ${ }^{1}$ \\ ${ }^{1}$ Department of Chemical Engineering, Nnamdi Azikwe University, Awka Anambra State, \\ Nigeria \\ ${ }^{2}$ Department of Chemical Engineering, Federal University Ndufu Alike, Ebonyi State, Nigeria
}

(Received February 9, 2019; Revised December 24, 2019; Accepted February 6, 2020)

\begin{abstract}
Statistical optimization was used to optimize corrosion inhibition efficiency of Sapium ellipticum leaf extract as corrosion inhibitor of aluminum in acid medium. Response surface methodology was applied, and the effects of four independent variables; acid concentration, inhibitor concentration, temperature, time, and their expected responses were determined. Central composite design a statistical tool was used to generate a total of 16 individual experimental runs, which was previously design to study the effects of these variables during corrosion process. The uniqueness of the model was scrutinized with various criteria including coefficient of determination $\left(\mathrm{R}^{2}=0.987\right), p$ value $(<0.0001)$, adequate precision $(30.22)$ and coefficient of variation $(5.30)$. The RSM is well fitted in the model which adequately predicted the optimum inhibition efficiency of $96.73 \%$ at optimum inhibitor concentration of $1.5 \mathrm{~g} / \mathrm{L}^{-1}$, acid concentration $1 \mathrm{M}$, temperature of $303 \mathrm{~K}$ and time of 6 hours. Also the electrochemical concept signifies that Sapium ellipticum acts as a mixed-kind inhibitor. The experimental data obtained is in conformity with other research works.
\end{abstract}

KEY WORDS: Sapium ellipticum, Acid corrosion, Electrochemical study, Response surface methodology

\section{INTRODUCTION}

Hydrochloric acid solutions are generally employed in oil and gas operations for de-scaling, cleaning, elimination of scales and rust in metallurgical and material sections. During these operations, aluminum surfaces are severely influenced by corrosion phenomenon to varying degrees [1-3]. To mitigate the effect and prolong the life span of metallic materials, corrosion scientists introduce inhibitors to the corrosive environment during these industrial processes. The use of corrosion inhibitor is the most convenient, simple and possible method to protect metallic materials in corrosive environments. Aluminum surface modification with synthesized inhibitor has been design to promote its anticorrosion resistance. Usually a reasonable quantity of synthesized inhibitors are been used for aluminum surface coatings in hostile flow streams. The synthesized inhibitors greatly protects aluminum surface from degrading by forming a thick and stable film layer. Inhibition phenomenon depends on the composition of the synthesized inhibitor, nature of corrosive ecosystem and coarseness of the metal.

Different categories of inhibitors are hazardous to the environment and aquatic lives. Hence, this justification strongly frustrates the utilization of imported corrosion inhibitors in process industries. As an alternative to the toxic organic inhibitors, compounds such as amino acids, ionic liquids, natural polymers and bio extracts, that are less toxic to humans and natural environments have been advocated for mitigation of corrosion [4-8]. This greener approach has received significant attention owing to its availability, low cost and to the best of our knowledge little or no negative effect on the environments has been documented [9-10].

*Corresponding author. E-mail: anadebe.valentine@funai.edu.ng ; anadebechika@gmail.com This work is licensed under the Creative Commons Attribution 4.0 International License 
Studies have proved that extracts from various plants are effective in obstructing metals corrosion in aggressive environments (Table 1). As presented in Table 1, optimum inhibition efficiency above $90 \%$ is attainable with plant extracts. The inhibitive action of plant extracts is due to the existence of organic molecules in their composition [11-12]. The heteroatoms $(\mathrm{N}, \mathrm{S}$, and $\mathrm{O}$ ), conjugated bonds and aromatics serve as the interaction centers between plants extracts and metallic surfaces [13].

Response surface methodology (RSM) is a known computer software and statistical tool, which has been useful for optimizing various processes in which a response of interest is influence by many independent variables. It makes use of mathematical codes and statistical technique ranging from high, medium and low levels for modeling, optimization and factor evaluation in complex interactions of processes. The justification of this unique software program is to optimize the responses while reducing the number of experimental runs needed to generate accurate statistical data.

Sapium ellipticum belongs to the family Euphorbiaceae and is usually classified as jumping seed tree. It is a unique plant in the traditional medicine for treatment of series of diseases including diabetes. It is cultivated in the eastern and tropical Africa. The medicinal activities of Sapium ellipticum leaves are attributed to the existence of the heterocyclic compounds/ phytochemical constituents in the plant.

Table 1. Studies on biomaterials as inhibitor for different metals in corrosive environments.

\begin{tabular}{|l|l|l|l|l|l|}
\hline Plant extract & Metal & Acid environment & IE (\%) & Optimum concentration & Ref. \\
\hline Areca palm leaf & $\mathrm{Al}$ & $0.5 \mathrm{M} \mathrm{HCl}$ & 89 & $6 \mathrm{~g} / \mathrm{L}$ & {$[14]$} \\
\hline Aspilia africana & $\mathrm{Al}$ & $0.5 \mathrm{M} \mathrm{HCl}$ & 95 & $700 \mathrm{mg} / \mathrm{L}$ & {$[15]$} \\
\hline Cordia dichotoma & $\mathrm{Al}$ & $0.5 \mathrm{M} \mathrm{HCl}$ & 95 & $1.05 \mathrm{~g} / \mathrm{L}$ & {$[16]$} \\
\hline Asparagus racemosus & $\mathrm{Al}$ & $1.0 \mathrm{M} \mathrm{HCl}$ & 74 & $600 \mathrm{mg} / \mathrm{L}$ & {$[17]$} \\
\hline Pigeon pea leaf & $\mathrm{MS}$ & $1.2 \mathrm{M} \mathrm{HCl}$ & 91 & $0.9 \mathrm{~g} / \mathrm{L}$ & {$[18]$} \\
\hline Rosa canina fruit & $\mathrm{MS}$ & $1.0 \mathrm{M} \mathrm{HCl}$ & 86 & $800 \mathrm{mg} / \mathrm{L}$ & {$[19]$} \\
\hline Orange zest (oil) & $\mathrm{MS}$ & $1.0 \mathrm{M} \mathrm{HCl}$ & 76 & $2.5 \mathrm{~g} / \mathrm{L}$ & {$[20]$} \\
\hline Cuscuta reflexa & $\mathrm{MS}$ & $0.5 \mathrm{M} \mathrm{H}_{2} \mathrm{SO}_{4}$ & 95 & $500 \mathrm{mg} / \mathrm{L}$ & {$[21]$} \\
\hline Chicken nail & $\mathrm{MS}$ & $2 \mathrm{M} \mathrm{H}_{2} \mathrm{SO}_{4}$ & 74 & $0.1 \mathrm{~g} / \mathrm{L}$ & {$[22]$} \\
\hline Bistorta officinalis & $\mathrm{CS}$ & $\mathrm{Cooling} \mathrm{water}$ & 95 & $1000 \mathrm{mg} / \mathrm{L}$ & {$[23]$} \\
\hline Black pepper & $\mathrm{CS}$ & $1.0 \mathrm{M} \mathrm{HCl}$ & 93 & $2.0 \mathrm{~g} / \mathrm{L}$ & {$[24]$} \\
\hline Pterocarpus santalinoide & $\mathrm{CS}$ & $1.0 \mathrm{M} \mathrm{HCl}$ & 90 & $0.7 \mathrm{~g} / \mathrm{L}$ & {$[25]$} \\
\hline
\end{tabular}

\section{EXPERIMENTAL}

\section{Preparation of the extract}

Fresh Sapium ellipticum leaf sample were sourced from Sapium ellipticum orchard at Uli in Anambra State of Nigeria. $1.0 \mathrm{~kg}$ of leaves was collected from matured plants. The sample leaves were conveyed in a plastic bag to the laboratory. At the start of the experiment the samples were washed under running water and sun-dried for 4 days in a control environment. It was thereafter ground into powder and stored in sample bottle for extraction process. The extraction process was carried in batches. $30 \mathrm{~g}$ of the Sapium ellipticum leaf powder were weighed and immersed in $1000 \mathrm{~mL}$ of ethanol for 48 hours. Sieving of the mixture was achieved with a Whatman filter paper of $24.0 \mathrm{~cm}$. The resulting filtrate was subsequently reduced in volume with a rotary evaporator at $40{ }^{\circ} \mathrm{C}$. Final elimination of solvent and drying was done using a regulated water bath at $40{ }^{\circ} \mathrm{C}$ [26]. The $\mathrm{HCl}$ (JHD) and ethanol (JHD) used for the practical were of high grade. 
Metals preparation

Corrosion studies were performed on aluminum sheet of compositions $\mathrm{Pb}(0.064 \%), \mathrm{Mn}$ (1.22\%), Si (0.3\%), Cu (0.077\%), Ti (0.026\%), V (0.09\%), Fe (0.55\%) and $\mathrm{Al}(97 \%)$. Prior to corrosion process, the aluminum was mechanically cut. The surface of each coupon were then polished using 220,800 and 1200 emery papers to obtain a smooth area. The coupons were further degreased with acetone rinsed with distilled water to remove debris and dry in warm air according to previous work done [27].

\section{FTIR analysis}

Prior to the experiment, FTIR analysis was carried out on the neat sample Sapium ellipticum (SE) to identify the active functional group. Al coupons were further introduced in the inhibited medium. After the corrosion investigation, corrosion particles were scoop, mixed with KBR (potassium bromide) and subjected to infrared spectroscopy using (SHIMADZU Model FTIR84008 ) to identify the functional group in the corrosion products.

\section{Weight loss method}

Weight loss method was performed at temperatures of 303, 318 and $333 \mathrm{~K}$, respectively. As previously expressed [28] the variation in the initial and last weight was studied for unprotected and protected test solution. At the end of corrosion study, Al coupons were removed, dipped in acetone, cleaned and finally re-weighed. The experimental data were recorded and evaluated using the equations (1), (2), (3) and (4) as adopted from literature [29].

$$
\begin{aligned}
& \Delta w=w_{i}-w_{f} \\
& C_{R}=\frac{w_{b l}-w_{i n h}}{\operatorname{Area}\left(m^{2}\right) \mathrm{x} \text { time }} \\
& I E \%=\frac{w_{b l}-w_{i n h}}{w_{b l}} \times \frac{100}{1} \\
& \theta=\frac{w_{b l}-w_{i n h}}{w_{b l}}
\end{aligned}
$$

where $\Delta w$ represent weight loss, $w_{i}$ and $w_{f}$ are initial and final weight of the coupons, $\mathrm{C}_{\mathrm{R}}$ is the corrosion rate, $I E \%$ is the inhibition efficiency, $\theta$ is the total surface coverage, $w_{b l}$ and $w_{i n h}$ are the weight loss values obtained in the blank solution and inhibited medium. Area denotes area of aluminum and time denotes time of study.

\section{Electrochemical method}

Thorough electrochemical test was performed using a VERSASTAT 400 full set DC Voltammetry and Corrosion System, with V3 Studio software. The electrochemical impedance study was carried out over a frequency range of $0.1-10 \mathrm{mHz}$ with a signal amplitude perturbation of $10 \mathrm{mV}$. The potentiodynamic/Galvanostat Corrosion System with E-chem software was used for the polarization study, considering $\pm 250 \mathrm{mV}$ versus $\mathrm{E}_{\text {corr }}$ and scanning rate of $0.333 \mathrm{mV} / \mathrm{s}$. In this area of study a graphite bar and a saturated calomel electrode (SCE) were employed as reference electrodes. Aluminum specimen of $1 \mathrm{~cm}^{2}$ was used as working 
electrode.The experiments was performed in aerated and unstirred solution at the end of 1 hour of immersion at $303 \mathrm{~K}$. To investigate the optimum and minimum concentration of SE extract on aluminum coupon in $1 \mathrm{M} \mathrm{HCl}$, varying concentrations of $0.3 \mathrm{~g} / \mathrm{L}$ and $1.5 \mathrm{~g} / \mathrm{L} \mathrm{SE}$ were used. All data was run in triplicate for reproducibility of average values and further statistical analysis. This was evaluated using eq. (5).

$$
I E \%=\frac{i_{\operatorname{Corr}(b l)-} i_{\operatorname{Corr}(i n h)}}{i_{\operatorname{Corr}(b l)}}
$$

Where $i_{c o r r(b l)}$ and $i_{c o r r(i n h)}$ are the current density values in the absence and presence of inhibitor.

\section{Surface characterization}

Morphological analysis of the corroded coupons were carried out at Chemical Engineering Department, Ahmadu Bello University, Zaria using the scanning electron microscope (SEM of model no MVE016477830), Netherlands.

\section{RESULTS AND DISCUSSION}

\section{Phytochemical examination}

Phytochemical test is a vital area of study as regards to plant derived materials. Standard titrimetric method was used to identify vital bioactive ingredients existing in crude SE extracts. It was observed that the extract is rich in flavonoids $(+)$, phenolics $(+)$, alkaloids $(+)$, saponins $(-)$, tannins $(+)$, terpenoids $(+)$, steroids $(+)$. These bioactive ingredients have anti-inflammatory and anti-oxidant characteristics, which justified anti-corrosion performance of SE extract. Polyphenolic compound like flavonoids and phenolic acids mainly exist in large amount in dried leaves. Flavonoids naturally exist in plants based materials as response to microbial disease having a benzo- $\gamma$-pyrone ring structure [30]. Phenolics are group of compound obtained from hydroxycinnamic and hydroxybenzoic acid existing in dry plants or leaves containing enough Gallic acid as the most constituent [31]. Alkaloids are class of constituents that contain some basic nitrogen atoms like 4'-hydroxyphenylethanamide- $\alpha$-L-rhamnopyranoside, $\quad \mathrm{N}, \alpha-\mathrm{L}$ rhamnopyranosyl vincosamide and phenylacetonitrile pyrrolemarumine derivatives [32-33]. The green flavor (carotenoid) from Sapium ellipticum leaf extract has a bitter taste due to the high composition of tannins and categories of complex compounds existing as "triterpenes". Tannins are well known to contain polyphenolic moieties which form tanninate salts with ferric ions. The inhibition activity of tannins is attributed to the formation of a dense cross-linked film of ferric tanninate salts that shield the steel surface. In same vain, triterpenes contain some vital functional groups like $\mathrm{O}-\mathrm{H}, \mathrm{C}=\mathrm{C}, \mathrm{C}=\mathrm{O}$ which are diagnostic makers of aliphatic and aromatics family.

\section{FTIR analysis of Sapium ellipticum leaf extract and corrosion products}

FTIR analysis have been useful to obtain vital information about the mutual interactions between the adsorbed $\mathrm{SE}$ and $\mathrm{Al}$ surface immersed in $1 \mathrm{M} \mathrm{HCl}$ at $1.5 \mathrm{~g} / \mathrm{L}$ inhibitor concentration. The inhibitive strength depends much on the molecular structure of the SE molecules. Figure 1a and 1b signify the FTIR spectrum of pure SE extract and Al in protected medium. As revealed in Figure 1a the peaks indicate the presence of various categories of functional groups. There is every possibility that there is presence of carboxylic acid existing 
there. The range of the peaks numbers includes 3675.08, 3281.81, 3026.75, 2691.73, 2224.56, 1941.12, 1638.08, 1451.65, 1071.98, 948.56 and $652.18 \mathrm{~cm}^{-1}$. Similar observations were documented by [34]. This proves that SE active species contains complex molecules. In Figure $1 \mathrm{~b}$ after immersion in $1 \mathrm{M} \mathrm{HCl}$ solution most of the peaks numbers was seen to deviate from their initial position. The variations in the intensities and peak numbers signifies great deal of activeness of SE to aluminum surface showing that the active SE molecules have synchronized with the $\mathrm{Al}^{3+}$ formed on the surface, leading to $\mathrm{Al}^{3+}$ extract complex formation on the $\mathrm{Al}$ surface which significantly assisted in the inhibition process.

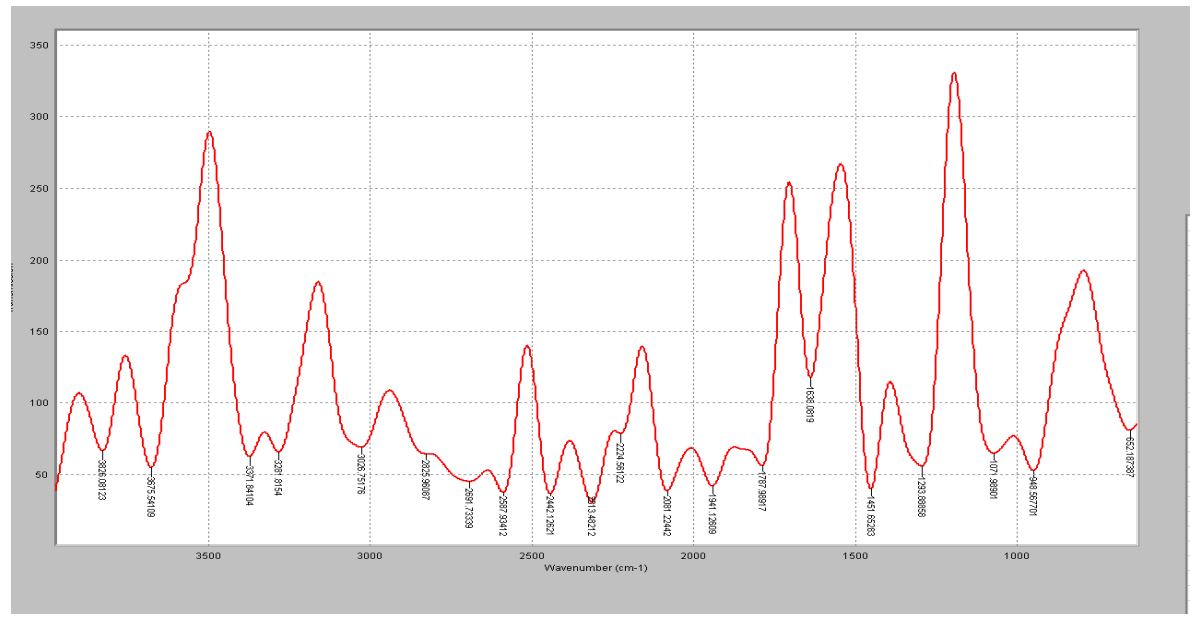

Figure 1. (a) FTIR of Sapium ellipticum leaf extract.

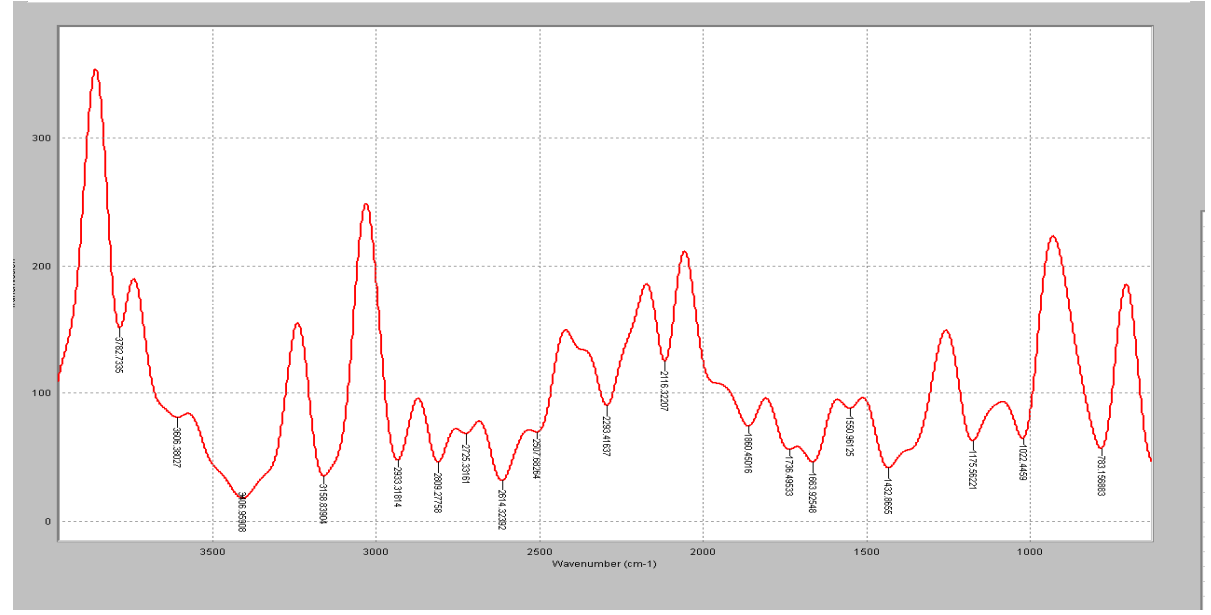

Figure 1. (b) FTIR of aluminum in $1 \mathrm{M} \mathrm{HCl}$ with Sapium ellipticum leaf extract. 
Weight loss evaluation

Mass loss for aluminum (AA3003) specimen in unprotected and protected medium was evaluated using [Eq. 1-3] as earlier stated. This method of corrosion evaluation is widely recommended due to its simplicity in nature. The results generated from this technique are listed in Table 2. Effects of inhibitor concentration, the SE extract exhibited unique inhibition efficiency of $96.73 \%$ and $91.39 \%$ in $1 \mathrm{M}$ and $2 \mathrm{M} \mathrm{HCl}$, respectively, at optimum concentration of $1.5 \mathrm{~g} / \mathrm{L}$. Further increment in SE extract concentration did not cause any pronounced change in the performance of the extract [35]. Effect of immersion time, the stability of the inhibitor on a time scale/weight loss measurement were evaluated in $1 \mathrm{M}$ and $2 \mathrm{M} \mathrm{HCl}$ in absence and presence of SE extract at varying concentrations for 3 to $6 \mathrm{~h}$ immersion time at varying temperatures [36]. The inhibition efficiency of SE extract was promoted with increasing the time of experiment from 3 to $6 \mathrm{~h}$. The increase in inhibition efficiency in $1 \mathrm{M}$ and $2 \mathrm{M} \mathrm{HCl}$ up to $6 \mathrm{~h}$ reflects unique adsorption mechanism of the constituents existing in SE extract on the $\mathrm{Al}$ surface, thus resulting in more protective layer formed at the $\mathrm{Al} / \mathrm{hydrochloric}$ acid solution interface. Effects of acid concentration, the irregularities in inhibition efficiency with increase in acid concentration from $1 \mathrm{M}$ to $2 \mathrm{M}$ are enumerated in Table 2. The gradual reduction in inhibition efficiency is very minimal, from $96.73 \%$ to $39.56 \%$. Such decrease in inhibition efficiency can be attributed to increase in hostile nature of acid solutions with an increase in concentration. High level of Al corrosion was recorded at 303-333 K, time of experiments from 3 to $6 \mathrm{~h}$. This is due to increase in the level of dissolution process of aluminum and partial desorption of $\mathrm{SE}$ molecules from the $\mathrm{Al}$ surface with temperature [37]. From the above discussion, SE mode of inhibition is in conformity with the literature and can be used as additive for mitigation of $\mathrm{Al}$ corrosion under service condition.

Table 2. Gravimetric results of aluminum specimen in $\mathrm{HCl}$ with inhibitor.

\begin{tabular}{|l|l|l|l|l|l|l|}
\hline \multirow{2}{*}{$\mathrm{SE}(\mathrm{g} / \mathrm{L})$} & \multicolumn{3}{|c|}{$1 \mathrm{M}$} & \multicolumn{3}{c|}{$2 \mathrm{M}$} \\
\cline { 2 - 7 } & $303 \mathrm{~K}$ & $318 \mathrm{~K}$ & $333 \mathrm{~K}$ & $303 \mathrm{~K}$ & $318 \mathrm{~K}$ & $333 \mathrm{~K}$ \\
\hline $0.3 \mathrm{~g} / \mathrm{L}$ & 62.42 & 57.48 & 39.56 & 53.65 & 49.59 & 44.06 \\
\hline $0.6 \mathrm{~g} / \mathrm{L}$ & 80.72 & 77.61 & 59.69 & 73.78 & 67.89 & 59.8 \\
\hline $1.2 \mathrm{~g} / \mathrm{L}$ & 90.44 & 88.3 & 70.38 & 84.47 & 77.61 & 66.78 \\
\hline $1.5 \mathrm{~g} / \mathrm{L}$ & 96.73 & 95.22 & 77.3 & 91.39 & 83.9 & 71.73 \\
\hline
\end{tabular}

Adsorption study

The mechanistic process of interaction between SE (inhibitor) and the Al surface can further be scrutinized by the adsorption models and the active compounds of the SE molecules on the $\mathrm{Al}$ surface is control by the characteristics and charge of the Al, structural characteristics of the inhibitor and class of electrolyte [38]. From the phytochemical analysis and FTIR study it revealed the existence of $\mathrm{N}$ and $\mathrm{O}$ heteroatoms, hydrocarbons and aromatic rings. The adsorption of SE molecules present in the extract block the surface of the aluminum (Al) against charge and mass transfer thereby impeding corrosion. Two modes of adsorption are generally known and considered. The neutral molecules of the extract may be adsorbed on the metal surface through chemisorption involving sharing of electrons between $\mathrm{O}$ and $\mathrm{N}$ atom and Fe and the substitution of water molecules from the metal surface. The components of the SE molecules could as well adsorb on the Al surface by pi electrons of the fused benzene rings and vacant D-orbital of iron [39]. On the contrary, the protonated components of the extracts inhibitor molecules may be physically adsorbed by electrostatic interactions between the cations and already adsorbed chloride ions. The process is based on a chemical phenomenon where SE molecule displaces the water molecule present on the Al surface and gets adsorbed [40]. 
$\operatorname{Org}_{(s o l)}+\mathrm{xH}_{2} \mathrm{O} \rightarrow \mathrm{Org}_{(a d s)}+\mathrm{xH}_{2} \mathrm{O}_{(\text {sol })}$

where, $\operatorname{Org}_{(\text {(sol) }}$ and $\operatorname{Org}_{(a d s)}$ are the organic molecules in aqueous solution and the adsorbed particles on the metallic surface, $\mathrm{H}_{2} \mathrm{O}_{(\mathrm{ads})}$ is the water molecules on the metallic surface, $\mathrm{X}$ is the size ratio representing the number of water molecules replaced by one molecule of organic adsorbate. The surface coverage depends on the inhibition efficiency and concentration level of the studied inhibitor. Experimental data of weight loss, EIS and polarization were best reflected in Langmuir adsorption isotherm [41-42]. Langmuir adsorption isotherm is presented in Equation (7)

$\mathrm{C} / \theta=1 / K_{a d s}+\mathrm{C}$

C represent concentration of inhibitor, $K_{a d s}$ denotes adsorption equilibrium. The adsorption parameters are listed in Table 3. As seen in Figure 2 the plot of $\mathrm{C} / \theta$ versus $\mathrm{C}$ yields a linear graph where the slope is near unity due to the surface adsorption of each SE molecule on individual active site on the aluminum surface. This mechanism of adsorption strongly conform to the Langmuir isotherm with a high correlation coefficient $\mathrm{R}^{2}(0.9944)$ and slope of about unity (1.1455). Normally, a higher range of $K_{a d s}$ move with higher trend to get adsorbed on $\mathrm{Al}$ surface. Also in Table 3, the results show that the activation energy in the absence of SE in $\mathrm{HCl}$ (unprotected solution) was found to be lower than the corresponding activation energies in the presence of different concentration of SE molecules. Further observation revealed that the activation energies increase as the concentration of SE molecules increases due to the spontaneous accumulation of SE molecules on steel surface which led to a considerable surface coverage and the film layer is seen to be higher than the dissolution of the Al surface.

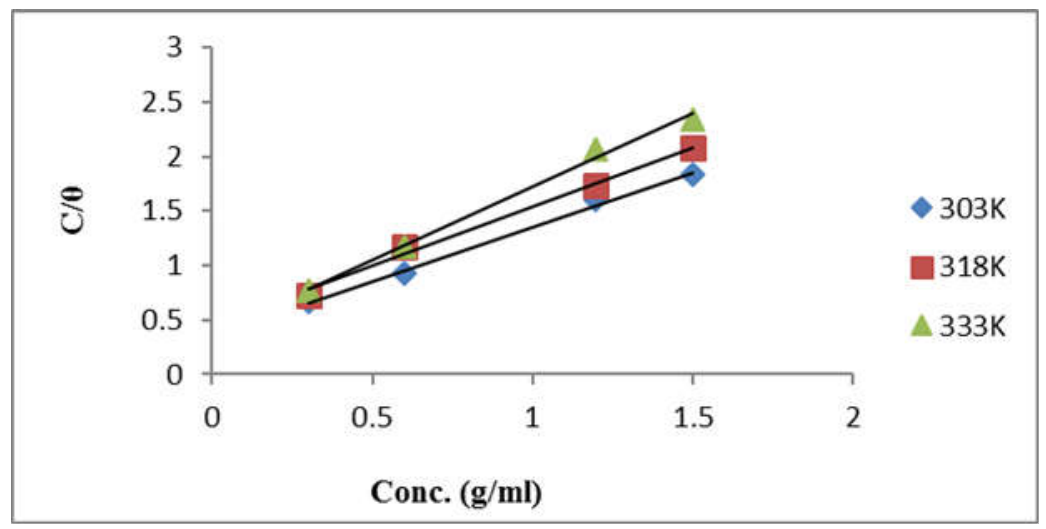

Figure 2. Langmuir isotherm for adsorption of $1.5 \mathrm{~g} / \mathrm{L} \mathrm{SE}$ on aluminum in $1 \mathrm{M} \mathrm{HCl}$.

\section{Polarization test}

Polarization test for $\mathrm{Al}$ in $1 \mathrm{M} \mathrm{HCl}$ in unprotected and protected medium in varying concentration of $0.3 \mathrm{~g} / \mathrm{L}$ and $1.5 \mathrm{~g} / \mathrm{L} \mathrm{SE}$ extract are shown in Figure 3a. It is evident that the studied inhibitor enhances the obstruction of anodic and cathodic discharge reactions. Table 4 shows the necessary electrochemical variables which includes corrosion current density $\left(\mathrm{I}_{\text {corr }}\right)$, corrosion potential $\left(\mathrm{E}_{\text {corr }}\right)$, Tafel slopes $(\beta \mathrm{a}, \beta \mathrm{c})$, level of surface coverage $(\theta)$ and inhibition efficiency (IE \%). It is seen that the existence of SE extract minimize $\mathrm{I}_{\text {corr }}$ because of the nature and adsorption of the active species of the SE extract while $\mathrm{E}_{\text {corr }}$ and tafel slopes do not have a 
significant change in the protected medium compared to unprotected medium. The immersion of the studied extract results to no considerable deviation in the $\mathrm{E}_{\text {corr }}$ values implying that the inhibitor acts as a mixed- kind inhibitor [43-44], invariably one can suggest that SE retards both oxidative dissolution process and reductive evolution of $\mathrm{H}_{2}$ gas. Further observation revealed that the phenomenon of dissolution is stabilized and the dissolution reaction is obstructed through adsorption phenomenon. Also the irregularity in the trend of $\beta a$ and $\beta c$ data shows the synergistic contribution of more than one class of molecules attached on the metal solution interface which led to a near perfect surface coverage.

Table 3. Langmuir adsorption parameter for aluminum in $1 \mathrm{M} \mathrm{HCl}$ with inhibitor.

\begin{tabular}{|l|l|l|l|l|l|}
\hline Temp $(\mathrm{K})$ & Log K & $\mathrm{K}$ & Slope & $\Delta \mathrm{G}(\mathrm{KJ} / \mathrm{mol})$ & $\mathrm{R}^{2}$ \\
\hline 303 & 0.3541 & 2.8241 & 1.0007 & -12.7354 & 0.9958 \\
\hline 318 & 0.4529 & 2.2080 & 1.0886 & -12.7152 & 0.9929 \\
\hline 333 & 0.3771 & 2.6518 & 1.3472 & -13.8221 & 0.9946 \\
\hline Mean & 0.3947 & 1.1455 & -13.0909 & 0.9944 \\
\hline Activation and heat of adsorption studies & Heat of adsorption $\left(\mathrm{Q}_{\text {ads }}\right) \mathrm{KJ} / \mathrm{mol}$ \\
\hline Conc. $\left(\mathrm{g} / \mathrm{L}^{-1}\right)$ & Activation energy $(\mathrm{Ea})$ & \\
\hline Blank & 34.21 & -6.90 & -16.19 \\
\hline 0.3 & 39.28 & -21.70 & \\
\hline 0.6 & 45.61 & -26.32 & \\
\hline 1.2 & 51.71 &
\end{tabular}

Electrochemical impedance spectroscopy

Impedance study provides vital information as regards to electrochemical systems [45]. Nyquist plots were generated for $\mathrm{Al}$ electrode immersed in $1 \mathrm{M} \mathrm{HCl}$ in the unprotected and protected medium with $0.3 \mathrm{~g} / \mathrm{L}$ and $1.5 \mathrm{~g} / \mathrm{L}$, respectively. Figure $3 \mathrm{~b}$ represents one, imperfect and depressed semi Nyquist plot whose middle displaced below the real axis. It is well known that virtually all impedance spectrums have a depressed semicircle which may be ascribed to the influence of frequency dispersion because of the dark flakes, coarseness and texture of the aluminum surface [46]. In this study there was a gentle increase in the circumference of the semicircle of the Nyquist plot as a result of the synergistic increase in the number of SE extract molecules when the concentration was elevated from $0.3 \mathrm{~g} / \mathrm{L}$ to $1.5 \mathrm{~g} / \mathrm{L}$. The increase in the circumference obviously showed that the $\left(\mathrm{R}_{\mathrm{ct}}\right)$ values were also enhanced from 300.5 to 3058 $\Omega \mathrm{cm}^{2}$ at the optimum concentration of $1.5 \mathrm{~g} / \mathrm{L}$. The considered variables in this study are listed in Table 4, such as $\mathrm{R}_{\mathrm{ct}}$, double layer capacitance $\left(\mathrm{c}_{d l}\right)$ and (IE \%). The $\mathrm{R}_{\mathrm{ct}}$ data were observe to increase while $\left(\mathrm{c}_{d l}\right)$ values gently reduces from $6.907 \times 10^{-5}$ to $6.018 \times 10^{-5} \mathrm{~F} \mathrm{~cm}^{-2}$ when the SE concentration increases [47]. This can be ascribed to the substitution of water molecules through adsorption of the SE active compounds on the Al surface, reducing the level of dissolution. High $\left(\mathrm{R}_{\mathrm{ct}}\right)$ values are connected with moderate dissolution systems [48]. Here, the major variables deduced from the analysis of the Nyquist spectra are resistance of charge transfer $\left(R_{c t}\right)$ and the double layer capacitance $\left(\mathrm{c}_{d l}\right)$ which is explained as

$\mathrm{C}_{d l}=1 /\left(2 \pi f_{\max } R_{\mathrm{ct}}\right)$

Here, $f_{\max }$ is the rate at which the imaginary part of the impedance is elevated-Zim (max). 

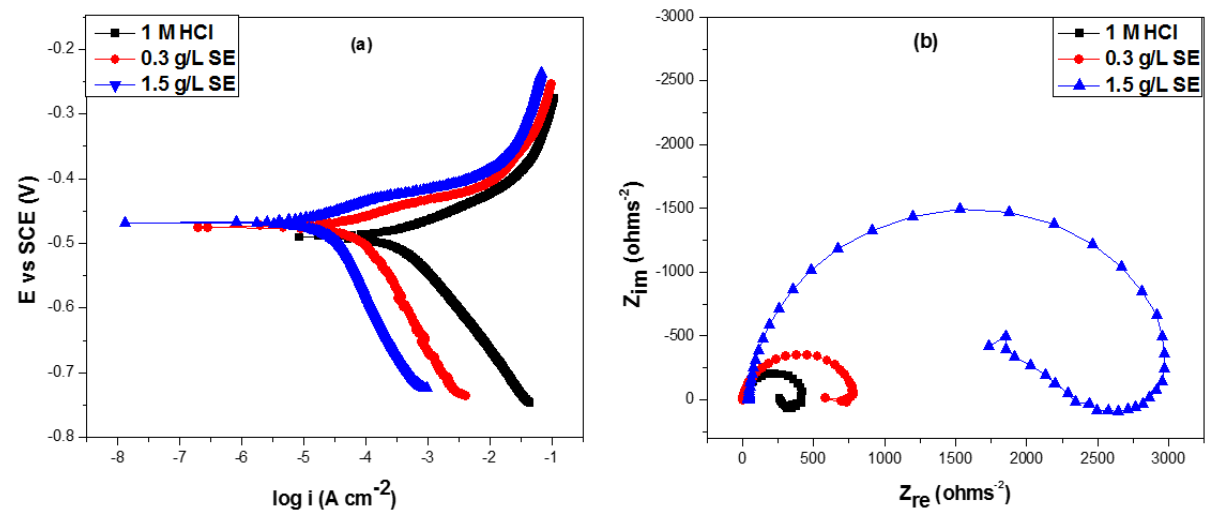

Figure 3. (a) Polarization curves of $\mathrm{Al}$ in $1 \mathrm{M} \mathrm{HCl} / \mathrm{SE}$ and (b) impedance spectra of $\mathrm{Al}$ in $1 \mathrm{M}$ $\mathrm{HCl} / \mathrm{SE}$.

Table 4. Tafel polarization measurement.

\begin{tabular}{|l|l|l|l|l|l|l|}
\hline System & $E_{\text {corr }}$ & $I_{\text {corr }}$ & $\beta c$ & $\beta a$ & $\Theta$ & IE (\%) \\
\hline $1 \mathrm{M} \mathrm{HCl}$ & -550 & 86.9 & 111 & 96.2 & - & - \\
\hline $1 \mathrm{M} \mathrm{HCl}+0.3 \mathrm{~g} / \mathrm{L} \mathrm{SE}$ & -549 & 48.3 & 104 & 72.6 & 0.432 & 43.2 \\
\hline $1 \mathrm{M} \mathrm{HCl}+1.5 \mathrm{~g} / \mathrm{L} \mathrm{SE}$ & -553 & 9.6 & 103 & 70.7 & 0.891 & 89.1 \\
\hline Electrochemical impedance data for aluminum in $1 \mathrm{M} \mathrm{HCl}$ \\
\hline System & $\mathrm{R}_{\mathrm{ct}}\left(\Omega \mathrm{cm}^{2}\right)$ & $\mathrm{n}$ & $\mathrm{C}_{d l}\left(\mathrm{~F} \mathrm{~cm}^{2}\right)$ & $\mathrm{IE}(\%)$ \\
\hline $1 \mathrm{M} \mathrm{HCl}$ & 300.5 & 0.89 & $6.907 \mathrm{E}-5$ & \\
\hline $1 \mathrm{M} \mathrm{HCl}+0.3 \mathrm{~g} / \mathrm{L} \mathrm{SE}$ & 760 & 0.88 & $6.978 \mathrm{E}-5$ & 60.5 \\
\hline $1 \mathrm{M} \mathrm{HCl}+1.5 \mathrm{~g} / \mathrm{L} \mathrm{SE}$ & 3058 & 0.88 & $6.018 \mathrm{E}-5$ & 90.2 \\
\hline
\end{tabular}

Optimization of IE\% of SE on Al alloy in HCl using response surface methodology

Using response surface methodology (RSM), the inhibition efficiency of SE extract was scrutinized and optimized by central composite design (CCD) tool of Design Expert Software (version 10). A total of 16 runs of experiments were conducted as presented in Table 5. The 3-D surface plot of efficacy of SE on aluminum alloy (AA3003) surface is presented in Figure 4. In this investigation, the validity of a model depends on some theory which was adequately explained below. Figure 4A denotes the actual and predicted plots; this is used for justification of the model's order. The plot generates a straight line graph having the experimental data points spread randomly on the $45^{\circ}$ line implying that the model gives adequate fitness for the experimental data. Figure 4B shows that Normal plot of residuals versus internally studentized residuals is normal and no variation was observed in the normality of the residuals, the theory of the normality of the residuals was adequately verified. Figure $4 \mathrm{C}$ is plot of externally studentized residual versus runs number. This chart reveals the independence between the residuals. When a process such as sinusoid is not significant in the chart, then the theory in question is approved. In this chart, no specific process display, isolate the independence of the residuals. Furthermore, nature of the 3-D surface plots suggests that there is a good correlation among the considered factors. Figure 4D shows that interactive effect of acid concentration and temperature is negative; enhancing these variables increases the chances of electrochemical reaction to occur which result to high dissolution of aluminum alloy (evolution of $\mathrm{H}_{2}$ gas). Figure $4 \mathrm{E}$ indicates that increase in the acid concentration expedite the speed of aluminum 
dissolution but on the contrary the level of mass loss declined on addition of inhibitor and the attachment of SE molecules and the surface coverage enhanced with elevated inhibitor concentration which led to a near perfect coverage as revealed from the SEM test. The maximum inhibition efficiency attained is $96.73 \%$. In Figure $4 \mathrm{~F}$ effect of temperature and SE concentration was highlighted, at elevated temperatures the heterocyclic bonds in SE molecules were dispersed which reduces the rate of surface attachment on the corroding surface, but enhancing the concentration of SE molecules results to a total coverage due to the spontaneous accumulation of the active compounds [49].
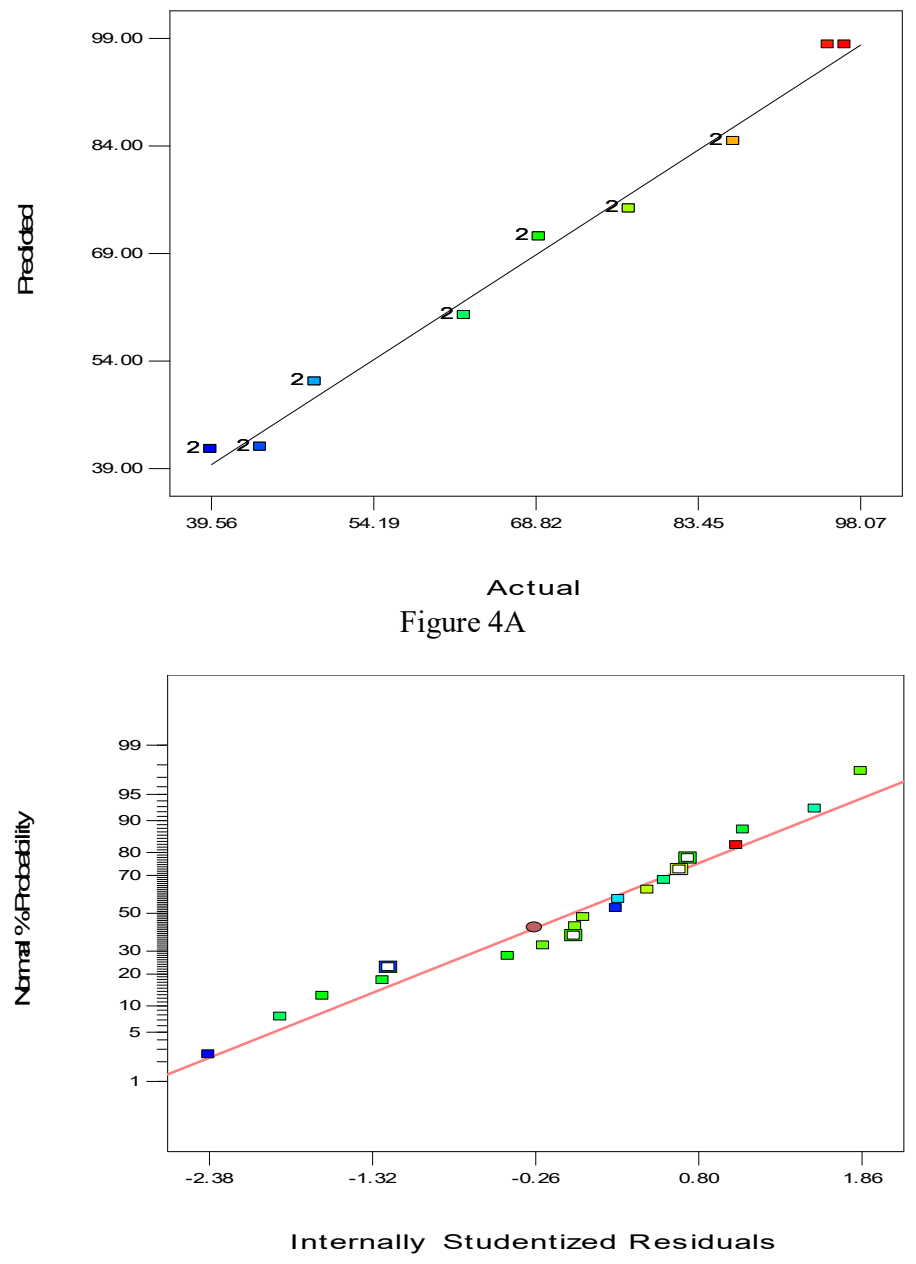

Figure 4B 

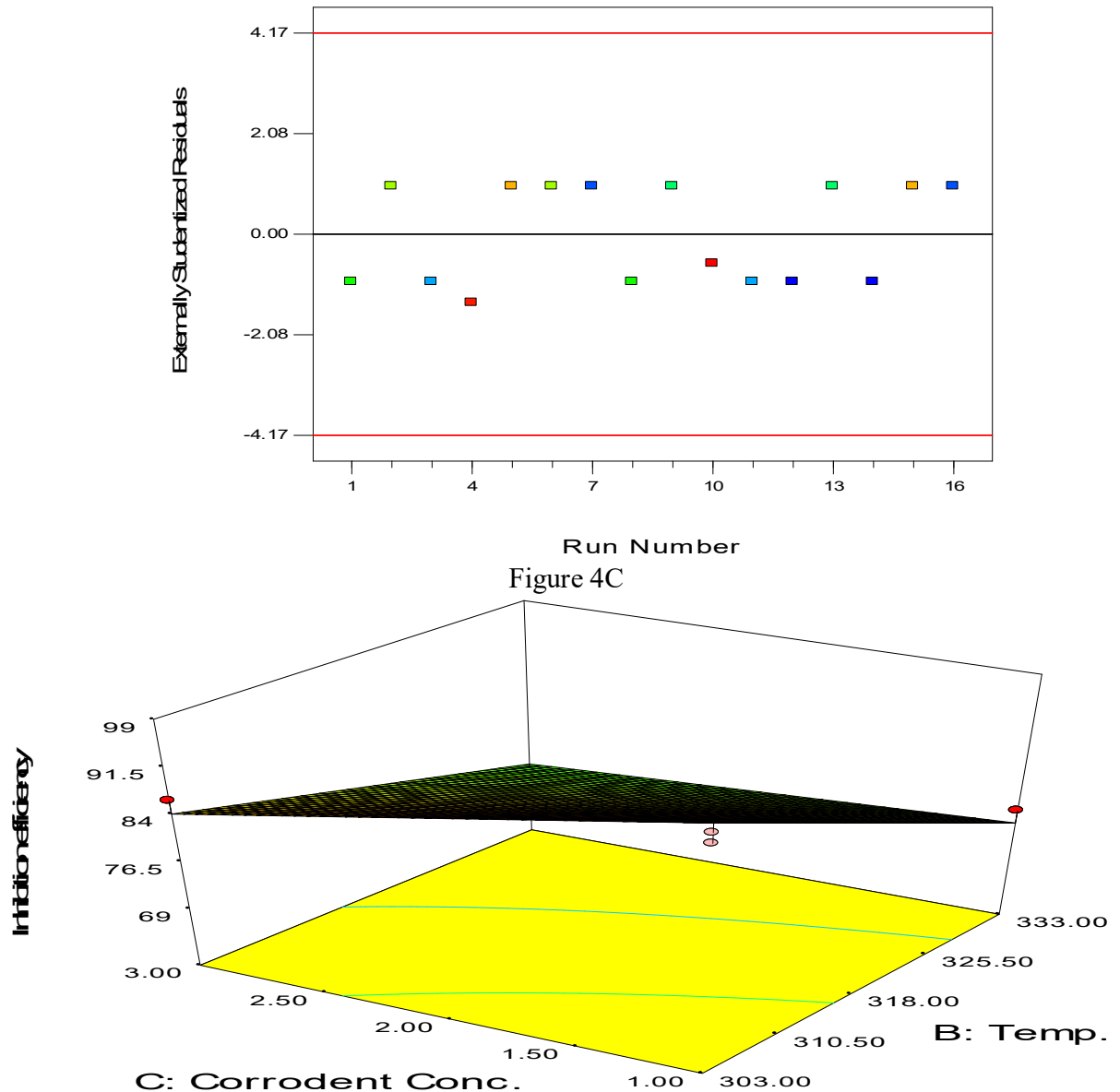

Figure 4D

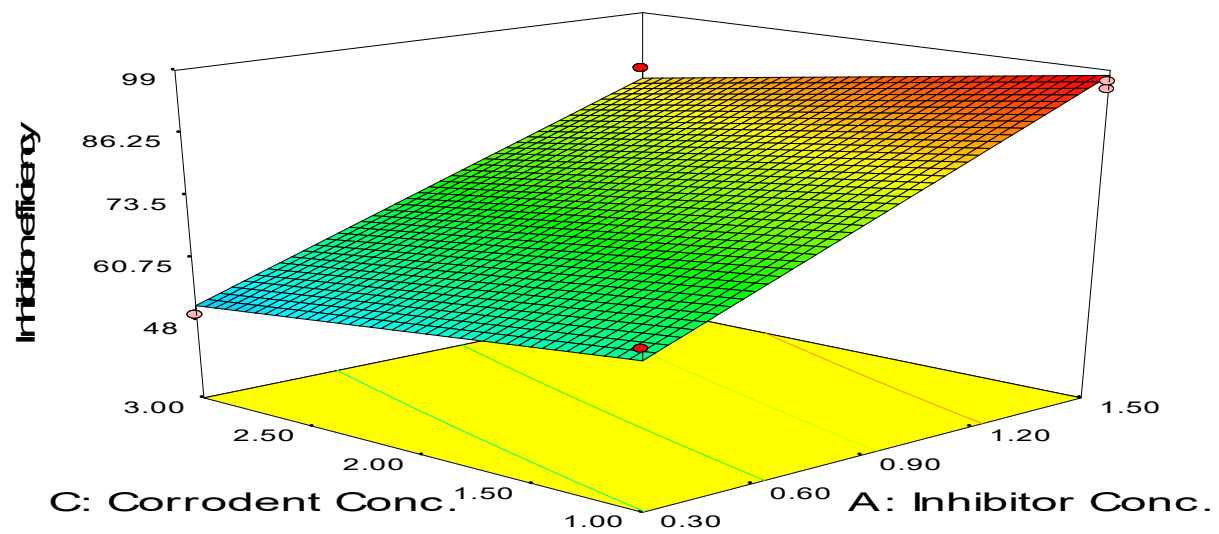

Figure 4E

Bull. Chem. Soc. Ethiop. 2020, 34(1) 


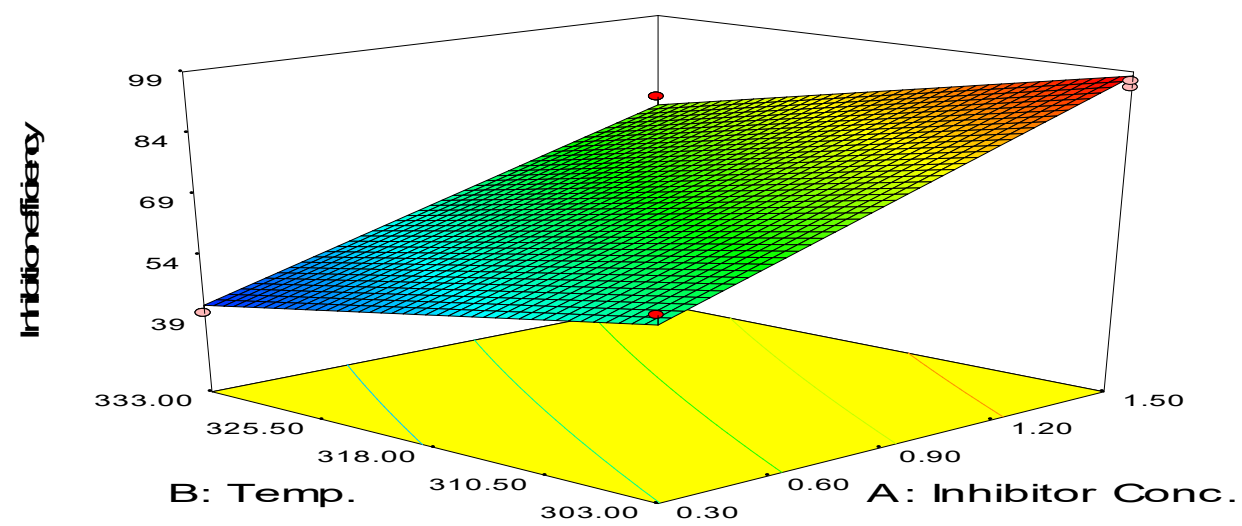

Figure 4F

Figure 4. Response surface optimization plots for inhibition efficiency using design expert version 10 (a) Predict versus actual plot for SE on Aluminum in $\mathrm{HCl}$, (b) normal plot of residuals versus internally studentized residuals for $\mathrm{SE}$ on $\mathrm{Al}$ in $\mathrm{HCl}$, (c) plot of externally studentized residual versus run number, (d) acid conc. versus temp, (e) acid conc. versus inhibitor conc. And (f) temp. versus inhibitor conc.

Table 5. Experimental range and levels of CCD for SE on aluminum alloy (AA3003) in $\mathrm{HCl}$.

\begin{tabular}{|l|l|l|l|l|l|}
\hline Run & $\mathrm{F}_{1}(\mathrm{IC}) \mathrm{g} / \mathrm{L}^{-1}$ & $\mathrm{~F}_{2}(\mathrm{~T}) \mathrm{K}$ & $\mathrm{F}_{3}(\mathrm{AC})$ & $\mathrm{F}_{4}(\mathrm{~h})$ & Response ${ }_{1} \mathrm{IE}(\%)$ \\
\hline 1 & 1.5 & 333 & 2 & 3 & 69.19 \\
\hline 2 & 1.5 & 333 & 1 & 6 & 77.3 \\
\hline 3 & 0.3 & 303 & 2 & 3 & 48.96 \\
\hline 4 & 1.5 & 303 & 1 & 6 & 95.22 \\
\hline 5 & 1.5 & 303 & 2 & 3 & 86.7 \\
\hline 6 & 1.5 & 333 & 1 & 6 & 77.3 \\
\hline 7 & 0.3 & 333 & 2 & 3 & 44.06 \\
\hline 8 & 0.3 & 333 & 2 & 6 & 69.19 \\
\hline 9 & 0.3 & 303 & 1 & 3 & 62.42 \\
\hline $\mathbf{1 0}$ & $\mathbf{1 . 5}$ & $\mathbf{3 0 3}$ & $\mathbf{1}$ & $\mathbf{6}$ & $\mathbf{9 6 . 7 3}$ \\
\hline 11 & 0.3 & 303 & 2 & 3 & 48.96 \\
\hline 12 & 0.3 & 333 & 1 & 6 & 39.56 \\
\hline 13 & 0.3 & 303 & 1 & 3 & 62.42 \\
\hline 14 & 0.3 & 333 & 1 & 6 & 39.56 \\
\hline 15 & 1.5 & 303 & 2 & 3 & 86.7 \\
\hline 16 & 0.3 & 333 & 2 & 3 & 44.06 \\
\hline
\end{tabular}

Statistical optimization of the corrosion inhibition study

The summary of p-values shows that a $2 \mathrm{FI}$ factorial approach fitted the ANOVA test, therefore linear and 2FI models were recommended. The factorial model equations obtained for the inhibition efficiency of $\mathrm{SE}$ molecules on aluminum in $\mathrm{HCl}$ is expressed in equation 9:

$\mathrm{IE} \%=+281.11894+68.67188 \mathrm{X}_{1}-0.74631 \mathrm{X}_{2}-52.39469 \mathrm{X}_{3}-0.11701 \mathrm{X}_{1} \mathrm{X}_{2}-1.75521 \mathrm{X}_{1} \mathrm{X}_{3}$ $+0.15937 \mathrm{X}_{2} \mathrm{X}_{3}$ 
The experimental results obtained for the inhibition process were statistically analyzed for the justification of the model's order. From the experiment, the ANOVA test shows that the F-valve is 122 which siginfies that the model is significant, this was justify by the p-value being less than 0.05 . P-valve is a statistical data employed to evaluate significance of the regression coefficients, it is useful for interpretation of good correlation among the independent variables and the expected responses. There is only a $0.01 \%$ chance that a "Model F-Value" this large could occur due to noise. The noise may be assigned to flow rates of the chemical constituents present in the inhibitor. Values of "Prob $>\mathrm{F}$ " less than 0.05 indicate model terms are significant. In this case $X_{1}, X_{2}, X_{3}, X_{1} X_{2}, X_{1} X_{3}, X_{2} X_{3}$ are significant model terms. The values of $R^{2}$ and $A d j$ $\mathrm{R}^{2}$ are close to unity, invariably suggesting that there is a good correlation between experimental and calculated results. In this model, the value of $\mathrm{R}^{2}(0.987)$ is in conformity with Adj $\mathrm{R}^{2}$ (0.979) indicating accurate statistical model. "Adeq Precision" method is employed to evaluate the signal-to-noise ratio. A situation a ratio is above 4 is acceptable. For this type of model the Adeq Precision was (30.22\%) which represent a high signal-to-noise ratio. Thus this model is therefore sufficient to navigate the design space. The final factorial model equations obtained for inhibition efficiency of $\mathrm{SE}$ on aluminum in $\mathrm{HCl}$ after eliminating the insignificant model terms becomes as expressed in equations (10).

$\mathrm{IE} \%=+65.52+16.77 \mathrm{X}_{1}-7.99 \mathrm{X}_{2}-3.29 \mathrm{X}_{3}-1.05 \mathrm{X}_{1} \mathrm{X}_{2}-1.05 \mathrm{X}_{1} \mathrm{X}_{3}+2.39 \mathrm{X}_{2} \mathrm{X}_{3}$

\section{Validation of experimental results}

In this investigation, statistical optimization of inhibition efficency of SE on aluminum alloy in acid medium was perfomed considering the independent variables. The justifcation of this study was to predict the optimal conditions in which maxmium inhibition efficency can be achieve. The inhibition efficency was predicted to be $96.73 \%$ which conforms with experimental data.

\section{Surface chemistry}

The AA3003 samples that were employed to investigate SE corrosion inhibition phenomenon in the acid medium were also scrutinized with (scanning electron microscopy) SEM. The surface chemistry for the corroded (unprotected and protected) are seen in Figure 5a and 5b.
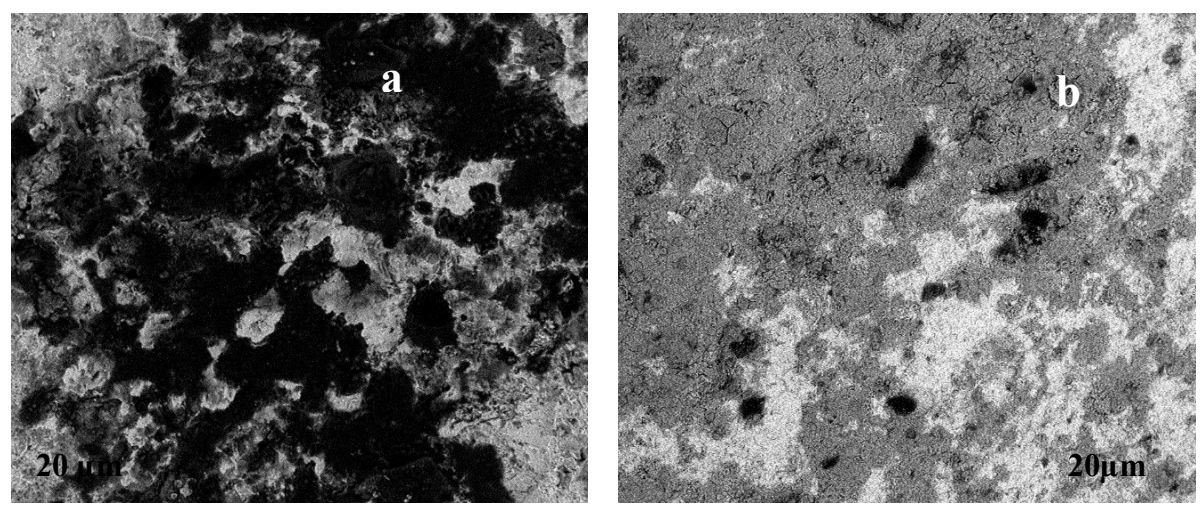

Figure 5. (a) Al alloy in blank solution and (b) $\mathrm{Al}$ alloy in protected medium ( $\mathrm{HCl} / \mathrm{SE})$.

The nature of the surfaces proves that SE extract prevents aluminum dissolution [50]. It is evident that (a) aluminum sample dipped in $1 \mathrm{M} \mathrm{HCl}$ without inhibitor experience a visible 
rough surface with cavities compared to (b) one with SE extract which evidence adsorption of inhibitor on the aluminum surface. This observation reconfirm with the mass loss experiment.

\section{CONCLUSION}

Based on the indices studied, the results showed that Sapium ellipticum leaf extract can be used as anti-corrosion additive for surface modification of aluminum alloy (AA3003) degradation under service conditions. The advantages are that the plant extract is renewable and ecofriendly, it do not contain toxic elements in their heterocyclic compounds. Furthermore, the following conclusions can be inferred from the study:

Sapium ellipticum is a friendly inhibitor for mitgation of aluminum corrosion in $1 \mathrm{M} \mathrm{HCl}$. The inhibition efficiency increases with SE active constituents and declined by elevating the temperature. The adsorption phenomenon is well fitted into langmuir isotherm and the thermodynamics investigation proves that immersion of SE enhances the activation energy. Impedance studies shows that the charge transfer resistance increases in protected medium and double layer capacitance values decline slightly. Response surface methodology approach describe the mutual correlation between the controllable variables and the expected responses thereby reducing number of experimental runs.

\section{REFERENCES}

1. Olusegun, A.K.; Tobunb, Y. Cocos nuclifera L. water as green corrosion inhibitor for acid corrosion of aluminium in $\mathrm{HCl}$ solution. Chinese Chem. Lett. 2010, 21, 1449-1452.

2. Khadraoui, A.; Khelifa, A.; Hachama, K.; Mehdaoui, R. Thymus algeriensis extract as a new eco-friendly corrosion inhibitor for 2024 aluminium alloy in $1 \mathrm{M} \mathrm{HCl} \mathrm{medium.} \mathrm{J.} \mathrm{Mol.}$ Liquid. 2016, 214, 293-297.

3. Gassama, D.; Diagne, A.A.; Yade, I.; Fall, M.; Faty, S. Investigations on the corrosion of constructional steels in different aqueous and simulated atmospheric environments. Bull. Chem. Soc. Ethiop. 2015, 29, 299-310.

4. Bader, A.; Shaheen, U.; Aborehab, M.A.S.; El Ouadi, Y.; Bouyanzer, A.; Hammouti, B.; Ben Hadda, T. Inhibitory effect of Acacia hamulosa methanol extract on the corrosion of mild steel in $1 \mathrm{M} \mathrm{HCl}$ acid. Bull. Chem. Soc. Ethiop. 2018, 32, 323-335.

5. Ashassi sorkhabi, H.; Seifzadeh, D. The inhibition of steel corrosion in hydrochloric acid solution by juice of Prunus cerasus. Int. J. Electrochem. Sci. 2006, 1, 92-98.

6. Abiola, O.K.; Otaigbe, J.O.E.; Kio, O.J. Gossipium hirsutum as extracts as green corrosion inhibitor for aluminum in $\mathrm{NaOH}$ solution. Corros. Sci. 2014, 81, 162-175.

7. Li, X.; Deng, S. Inhibition effect of Dendrocalamus brandisii leaves extract on $\mathrm{Al}$ in $\mathrm{HCl}$ and $\mathrm{H}_{3} \mathrm{PO}_{4}$ solutions. Corros. Sci. 2012, 65, 299-308.

8. Dhaundiyal, P.; Bashir, S.; Sharma, V.; Kumar, A. An investigation on mitigation of corrosion of mild steel by Origanum vulgare in acidic medium, Bull. Chem. Soc. Ethiop. 2019, 33, 159-168.

9. Alibakhshi, E.; Ramezanzaeh, M.; Haddadi, S.A.; Bahlakeh, G.; Ramezanzadeh, B.; Mahdavia M. Persian liquorice extract as a highly efficient sustainable corrosion inhibitor for mild steel in sodium chloride solution, J. Clean. Prod. 2019, 210, 660-672.

10. Sanaei, Z.; Bahlakeh, G.; Ramezanzadeh, B.; Ramezanzadeh, M. Application of green molecules from chicory aqueous extract for steel corrosion mitigation against chloride ions attack, the experimental examinations and electronic / atomic level computational studies. $J$. Mol. Liq. 2019, 290, Article ID 111176. 
11. Umoren, S.A.; Solomon, M.M.; Obot, I.B.; Sulieman, R.K. A critical review on the recent studies on plant materials as corrosion inhibitors for industrial metals. J. Ind. Eng. Chem. 2019, 76, 91-115.

12. Fang, Y.; Suganthan, B.; Ramasamy, R.P. Electrochemical characterization of aromatic corrosion inhibitors from plant extracts. J. Electroanal. Chem. 2019, 840, 74-83.

13. Mobin, M.; Basik, M.; Aslam, J. Pineapple stem extract as an environmental friendly novel corrosion inhibitor for low carbon steel in $1 \mathrm{M} \mathrm{HCl}$. Measurement 2019, 134, 595-605.

14. Raghavendra, N.; Ishwara Bhat J. Anticorrosion properties of Areca palm extract on $\mathrm{Al}$ in $0.5 \mathrm{M} \mathrm{HCl}$ environment. South Afr. J. Chem. 2018, 71, 30-38.

15. Ihebrodike, M.M.; Nwandu, M.C.; Okeoma, K.B.; Nnanna, L.A.; Chidiebere, M.A.; Eze, F.C.; Oguzie E.E. Experimental and theoretical assessment of the inhibiting action of Aspilia africana extract on corrosion aluminum alloy AA3003 in hydrochloric acid. J. Mater Sci. 2012, 47, 2559-2572.

16. Sharma, S., Sharma, Y.C. Cordia dichotoma as corrosion inhibitor for aluminium alloy in hydrochloric acid. Portgualiae Electrochim. Acta 2019, 37, 1-22.

17. Sumayah, B.; Garima, S.; Ashish, K. Shatavari (Asparagus racemosus) as green corrosion inhibitor of aluminum in acidic medium. Portgualiae Electrochim. Acta 2019, 37, 82-91.

18. Anadebe, V.C.; Onukwuli, O.D.; Omotioma, M.; Okafor, N.A. Experitmental, theortical modeling and optimization of inhibition efficency of pigeon pea leaf extract as anticorrosion agent of mild steel in acid environment. Mater. Chem. Phys. 2019, 233, 120-132.

19. Zahra, S.; Mohammad, R.; Ghazem, B.; Bahram, R. Use of Rosa canina fruit extract as a green corrosion inhibitor for mild steel in $1 \mathrm{M} \mathrm{HCl}$ solution: A complementary method, molecular dynamics and quantum mechanics investigation. J. Ind. Eng. Chem. 2019, 69, 1831.

20. Zakaria, B.; El Essiri, E.-H.; Sfaria, M.; Farah, A.; Touhami, M.E.; Hammouti, B. Extarction, characterization and anticorrosion potential of an essential oil from from orange zest as eco-friendly inhibitor for mild steel in acidic solution. J Bio Tribo Corro. 2019, 5, 84.

21. Akhil, S.; Dwarika, P.; Rajesh H. Investigation of corrosion inhibition effect and adsorption activities of Cuscuta reflexa extract for mild steel in $0.5 \mathrm{M} \mathrm{H}_{2} \mathrm{SO}_{4}$. Bioelectrochem. 2019, 124, 156-164.

22. Olawale, O.; Bello, J.O.; Ogunsemi, B.T., Uchella, U.C.; Oluyori, A.P.; Oladejo, N.K. Optimzation of inhibition efficiecny of chicken nail extracts as corrosion inhibitor of mild steel in $2 \mathrm{M} \mathrm{H}_{2} \mathrm{SO}_{4}$. Heliyon 2019, 5 e02821.

23. Zakiyeh, M.; Mansour, R. The use of green BIstorta officinalis extract for effective inhibiton of corrosion scale formation problems in cooling water system. J. Alloy Comp. 2019, 770, 669-678.

24. Dahmani, M.; Et-touhami, A.; Al-Deyab, S.S.; Hammouti, B.; Bouyanzer, A. Corrosion inhibition of $\mathrm{C} 38$ steel in $1 \mathrm{M} \mathrm{HCl}$ : A comparative study of black-pepper extract. Int. J. Electrochem Sci. 2010, 5, 1060-1069.

25. Ahanotu, C.C.; Onyeachu, I.B.; Solomon, M.M.; Chikwe, I.S.; Chikwe, O.B.; Eziukwu, C.A. Pterocarpus santalinoides leaves extract as sustainable chemistry as a sustainable and potent inhibtor for low carboon steel in a simulated picikling medium. Sust. Chem. Pharm. 2020, 15, 100196.

26. Khadom, A.A.; Ahmed, N.A.; Nagham, A.A. Xanthium strumarium leaves extracts as a friendly corrosion inhibitor of low carbon steel in $\mathrm{HCl}$ : Kinetics and mathematical studies. South Afr. J. Chem. Eng. 2017, 25, 13-21.

27. Khadom, A.A.; Hassan, A.F.; Abod, B.M. Evaluation of environmentally friendly inhibitor for galvanic corrosion of steel-copper couple in petroleum waste water. Process Safety. Environ. Protection 2015, 98, 93-101. 
28. Anadebe, V.C.; Onukwuli, O.D.; Omotioma, M.; Okafor, N.A. Optimization and electrochemical study on the control of mild steel corrosion in hydrochloric acid solution with bitter kola leaf extract as inhibitor. South Afr. J. Chem. 2018, 71, 51-61.

29. Nagm, N.; Kandile, N.G.; Badr, E.A.; Mohammed, M.A. Gravimetric and electrochemical evolution of environmentally friendly nonionic corrosion inhibitors for carbon steel in $1 \mathrm{M}$ HCl. Corros. Sci. 2012, 65, 94-103.

30. Kumar, S.; Pandey, A.K. Chemistry and biological activities of flavonoids: An over view. Sci. World J. 2013, Article ID 162750.

31. Prakash, D.; Suri, S.; Upadhyay, G.; Singh, B.N. Total phenol, anti-oxidant and free radical scavenging activities of some medicinal plants. Int. J. Food Sci. Nutr. 2007, 58, 18-28.

32. Panda, S.; Kar, A.; Sharma, P.; Sharma, A. Cardio-protective potentials of N, $\alpha-\mathrm{L}$ rhamnopyranosyl vincosamide, an indole alkaloid isolated from the leaves of Moringa oleifera in isoproterenol induced cardio toxic rats: In vivo and in vitro studies. Bioorg. Med. Chem. Lett. 2013, 23, 959-962.

33. Sahakitpichan, P.; Mahidol, C.; Disadee, W.; Ruchirawat, S.; Kanchanapoom, T. Unusual glycosides of pyrrole alkaloid and 4'-hydroxyphenylethanamide from leaves of Moringa oliefera. Phytochemistry 2011, 72, 791-795.

34. Selvi, A.; Rajendran, J.; Ganga-Sri, S.V.; John Amalraj, A.; Narayanasamy, B. Corrosion inhibition by beet root extract. Electrochim. Acta 2009, 27, 1-11.

35. Mokhtar, B.; Abdelkader, M.; Nora, B.; Mahieddine, N. Mild steel corrosion inhibition by parsley (Petroselium sativum) extract in acidic media. Egyptian J. Pet. 2019, 28, 155- 159.

36. Bashir, S.; Lgaz, H.; Chung, I.M.; Kumar, A. Potential of venlafaxine in the inhibition of mild steel corrosion in $\mathrm{HCl}$ : Insights from experimental and computational studies. Chem. Papers 2019, 73, 2255-2264.

37. Omotioma, M.; Onukwuli, O.D. Evaluation of Paw-paw leaves extract as anticorrosion agent for aluminum in $\mathrm{HCl}$. Nig. J. Technol. 2017, 36, 496-504.

38. Fouda, A.S.; Wahed, H.E. Corrosion inhibition of copper in $\mathrm{HNO}_{3}$ solution using thiophene and its derivatives. Arab. J. Chem. 2016, 9, S91-S99.

39. Odewunmi, N.A.; Umoren S.A.; Gasem, Z.M. Watermelon waste products as green corrosion inhibitors for mild steel in $\mathrm{HCl}$ solution. J. Environ. Chem. Eng. 2015, 3, 286-296.

40. Singh, A.; Ahamad, I.; Singh, V.K.; Quraishi, M.A. The effect of environmentally benign fruit extract of shahjan on the corrosion of mild steel in $\mathrm{HCl}$ solution. Chem. Eng. Comm. 2012, 199, 63-77.

41. Roland, T.L.; Celophas, A.L. Anti-corrosion properties of the symbolic effect of Rosmarinus officinalis and trypsin complex on medium carbon steel. Results Phys. 2018, 10, 99-106.

42. Bashir, S.; Sharma, V.; Lgaz, H.; Chung, I. M.; Singh, A.; Kumar, A. The inhibition action of analgin on the corrosion of mild steel in acidic medium: A combine theoretical and experimental approach. J. Mol. Liq. 2018, 263, 454-462.

43. Okafor, C.S.; Anadebe, V.C.; Onukwuli, O.D. Experimental, statistical modeling and molecular dynamics simulation concept of Sapium ellipticum leaf extract as corrosion inhibitor for carbon steel in acid environment. South Afr. J. Chem. 2018, 72, 164-175.

44. Bashir, S.; Thakur, A.; Lgaz, H.; Chung, I.M.; Kumar, A. Computational and experimental studies on phenylephrine as anti-corrosion substance of mild steel in acidic medium. J. Mol. Liq. 2019, 293, 111539.

45. Wang, H.; We, X.; Zhang, Y.; Ma, R.; Yin, Z.; Li, J. Electrochemical test and convection enhance mass transfer synergistic effect of $\mathrm{MnO}_{\mathrm{x}} / \mathrm{Ti}$ membrane electrode for alcohol oxidation. Chin. J. Chem. Eng. 2019, 27, 150-156.

46. Tao, Z.; He, W.; Wang, S.; Zhou, G. Electrochemical study of cypro-conazole as a novel corrosion inhibitor for copper in acidic solution. Ind. Eng. Chem. Res. 2013, 52, 17891 19899. 
47. Seifzadeh, D.; Valizadeh Pashabeigh, V.; Bezaatpour, A. 5-CM-salophen Schiff base as an effective inhibitor for corrosion of mild steel in $0.5 \mathrm{M} \mathrm{HCl}$. Chem. Eng. Comm. 2016, 203, 1279-1287.

48. Hsu, C.; Mansfeld, F. Concerning the conversion of the constant phase element parameter $\mathrm{Y}_{\mathrm{o}}$ into a capacitance. Corrosion 2001, 57, 747-748.

49. Kumar A., Bashir, S. Ethambutol: A new and effective corrosion inhibitor of mild steel in acid medium. Russian J. Appl. Chem. 2016, 89, 1158-1163.

50. Seifzadeh, D.; Basharnavas, H.; Bezaatpour, A. Schiff base compound as effective corrosion inhibitor for magnesium in acidic media. Mater. Chem. Phys. 2013, 138, 794-802. 